\title{
THE SERUM TRIHYDROXY-DIHYDROXY BILE ACID RATIO IN LIVER AND BILIARY TRACT DISEASE ${ }^{1}$
}

\author{
By JAMES B. CAREY, JR. \\ (From the Department of Medicine, University of Minnesota Medical School and Hospitals, \\ Minneapolis, Minn.)
}

(Submitted for publication April 10, 1958; accepted July 3, 1958)

Measurement of serum bile acid concentrations has long been expected to provide important information concerning hepatic and biliary tract disease because the formation and metabolism of these compounds is so closely associated with liver cell function. Contrary to expectations, however, serum bile acid determinations (chiefly cholic acid) have been of little value in the study of hepato-biliary disorders. After a careful study of serum cholates in liver disease, the conclusions of Sherlock and Walshe amply confirm this point (1). General experience, moreover, as listed in Table I, shows that there has been no uniform agreement concerning either the quantity or nature of the bile acids alleged to be present in normal serum. These shortcomings, rather than difficulties in quantitation, probably explain why serum bile acid determinations have not gained wider acceptance as a laboratory aid in the study of jaundice and liver disease.

In order to investigate these discrepancies, studies were done in this laboratory which showed that bile acids are demonstrable by paper chromatography in most normal human sera and that these acids are the same as those in bile and occur in approximately the same relative proportions $(2,3)$. A method for the simultaneous quantitation of the two major bile acid types was then devised and is described in the following sections. We found, as had previous investigators, that the serum concentrations of either the trihydroxy or dihydroxy bile acids were commonly elevated in patients with hepatobiliary disease, and although this information was not especially helpful, it soon became apparent that the ratio of the two main bile acid types often separated the patients into two groups. Those with predominantly hepatocellular injury had a trihydroxy-dihydroxy ratio of less than one, whereas those with obstructive jaundice

\footnotetext{
1 Supported in part by a grant (A-713) from the United States Public Health Service.
}

usually had a ratio of greater than one. The significance of this ratio was briefly described in an earlier communication (4) and has been confirmed in a recent study by Rudman and Kendall (5). These investigators separated trihydroxy and dihydroxy acids by column chromatography and found that the dihydroxy acids predominated in the sera of patients with Laennec's cirrhosis, whereas patients with obstructive jaundice tended to have higher concentrations of trihydroxy acids. Schiff (6) has reported similar results employing the method described in this paper.

\section{METHODS}

Certain features of the serum extractions described by Josephson (7) and Minibeck (8) were incorporated into a method employing alkaline hydrolysis. Briefly, this consists of precipitating serum proteins with alcohol and barium, separation of fats and neutral sterols from bile acids by partitioning between equal volumes of petroleum ether, ether, ethanol and water, and alkaline hydrolysis of the bile acids in the aqueous phase. The quantities of unconjugated trihydroxy and dihydroxy bile acids thus obtained were measured by ultraviolet spectrophotometry using the conditions described by Mosbach, Kalinsky, Halpern and Kendall (9) which permit a simultaneous differential analysis of these two bile acid types.

Preparation of reagents. The barium solution was prepared by adding $25 \mathrm{Gm}$. of anhydrous $\mathrm{Ba}(\mathrm{OH})_{2}$ to $400 \mathrm{ml}$. of distilled water. The solution was heated, filtered and then $4 \mathrm{Gm}$. of anhydrous barium acetate was added. After cooling, the saturated solution is stable for months. The concentration of the sodium hydroxide solution was 8 per cent by weight in water. The 65 per cent sulfuric acid solution was prepared by combining $169 \mathrm{ml}$. reagent grade concentrated sulfuric acid ( 95 to 98 per cent) with distilled water in a $250 \mathrm{ml}$. volumetric flask. The petroleum ether used was Skelly Solve B (boiling point 60 to 68). It was found that peroxides greatly distort the bile acid absorption spectrum and hence it is important that the ether be peroxide free.

Procedure. One $\mathrm{ml}$. of barium solution was added to $26 \mathrm{ml}$. of 95 per cent ethanol in a $50 \mathrm{ml}$. centrifuge tube marked at $30 \mathrm{ml}$. (Tube A, Figure 1). To this mixture, $3 \mathrm{ml}$. of serum was added drop by drop while stirring vigorously. The mixture was boiled for two minutes and 
TABLE I

Normal serum bile acid concentrations obtained by different methods

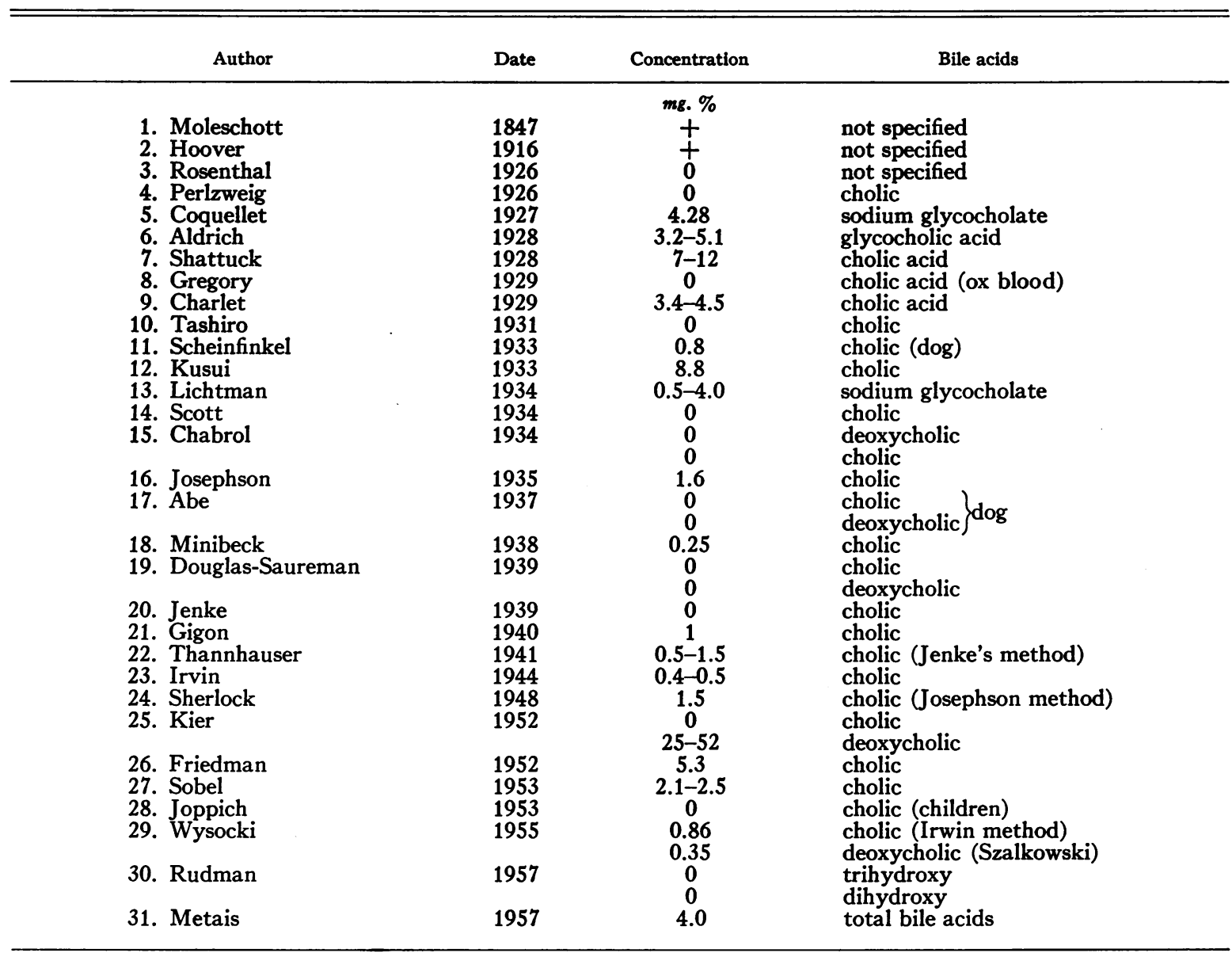

cooled in ice water. After centrifugation for 20 minutes at $3,000 \mathrm{rpm}$, the volume was adjusted to $30 \mathrm{ml}$. with ethanol and $25 \mathrm{ml}$. of the clear supernate was removed to a second tube (Tube B, Figure 1) and evaporated with reduced pressure in a tube heater. The residue was dissolved in $10 \mathrm{ml}$. of 50 per cent ethanol which had been previously equilibrated with equal volumes $(25 \mathrm{ml}$.) of ethyl ether and petroleum ether. The $\mathrm{pH}$ was adjusted to less than 3.5 (Congo red paper) by the addition of about $0.1 \mathrm{ml}$. concentrated $\mathrm{HCl}$. This solution was then extracted with the petroleum ether-ethyl ether phase which had been used for the equilibration. The ether phase was extracted with fresh, equilibrated 50 per cent ethanol and the combined aqueous ethanol phases were brought to a neutral $\mathrm{pH}$ with 8 per cent $\mathrm{NaOH}$ and then evaporated with reduced pressure in the tube heater to near dryness. Care was taken to avoid complete dryness, as baking makes the residue difficult to dissolve. To the residue from the aqueous phase, $5 \mathrm{ml}$. of 8 per cent $\mathrm{NaOH}$ was added, stirred to assure complete solution and placed in a pressure cooker at 15 pounds pressure for three hours. The resulting hydrolysate was then diluted with $5 \mathrm{ml}$. of distilled water, the $\mathrm{pH}$ was adjusted with concentrated $\mathrm{HCl}$ to less than 3.5 (Congo red paper) and extracted four times with $20 \mathrm{ml}$. volumes of ethyl ether. The ether phase was collected in a clean dry tube (Tube $\mathrm{C}$, Figure 1) and after washing with water, was evaporated to complete dryness. To this residue, $5 \mathrm{ml}$. of 65 per cent sulfuric acid was added and the tube was immediately heated at $60^{\circ}$ for exactly 15 minutes. After 10 minutes of cooling in ice water, the acid solution was filtered through a $2 \mathrm{~cm}$. medium sintered glass funnel. The filtrate was poured into a quartz cuvette and the absorption spectrum determined at $10 \mathrm{~m} \mu$ intervals from 220 to $410 \mathrm{~m} \mu$ against 65 per cent sulfuric acid which was also heated at 60 degrees for 15 minutes. A Beckman DU spectrophotometer with hydrogen lamp and blue phototube was used.

Calculations. The observed optical densities were corrected for background absorption to obtain the true optical density using calculations similar to those described by Brice and Swain (10). To make the correction a constant was calculated from pure bile acid solutions which is independent of concentration and hence can be used to determine true optical density when the background absorption 


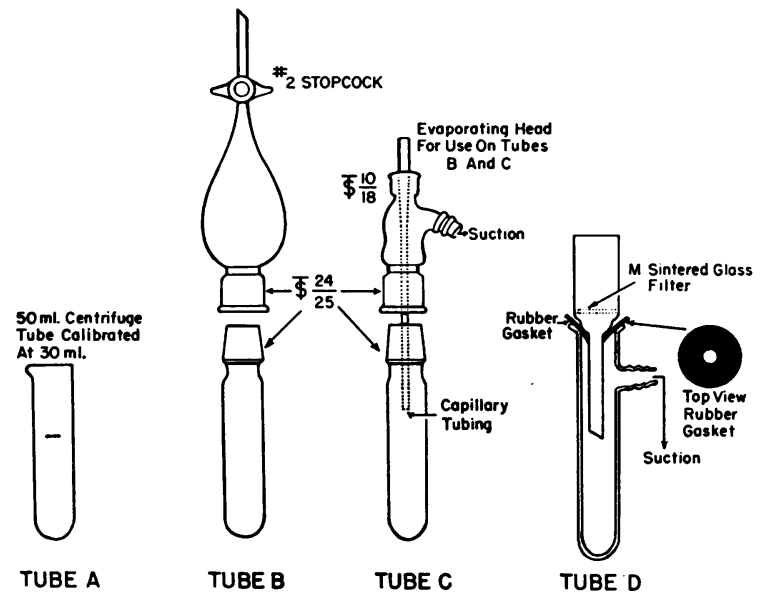

Fig. 1. Glassware Used for Serum Bile Acm DETERMiNATIONS

of the solution and the concentration of the bile acids is unknown. Such a constant relates the optical density at maximum absorption to the average of two equidistant optical densities. Thus from the absorption spectra of $175 \mu \mathrm{g}$. samples of pure cholic and chenodeoxycholic acids dissolved in 65 per cent $\mathrm{H}_{2} \mathrm{SO}_{4}$ and heated for 15 minutes at $60^{\circ}$ (Figure 2) the optical density at the wave length of maximum absorption for cholic acid was $\mathrm{E}^{0}{ }_{320}=1.24$ and the values $20 \mathrm{~m} \mu$ on either side of the maximum were $\mathrm{E}^{0}{ }_{300}=0.775$ and $\mathrm{E}_{310}=0.215$. For chenodeoxycholic acid the values were $\mathrm{E}_{380}^{0}=1.78, \mathrm{E}_{360}^{0}=1.20$ and $\mathrm{E}_{400}^{0}=$ 0.185. The constant for cholic acid which relates the maximum optical density at $320 \mathrm{~m} \mu$ to the average of two equidistant optical densities was obtained from the expression

$$
\begin{aligned}
& \frac{\mathrm{E}^{0}{ }_{320}}{\mathrm{E}^{0}{ }_{320}-1 / 2\left(\mathrm{E}^{0}{ }_{300}+\mathrm{E}^{0}{ }_{340}\right)} \\
& =\frac{1.24}{1.24-1 / 2(0.775+0.215)}=1.67 ;
\end{aligned}
$$

the constant for chenodeoxycholic acid was similarly computed,

$$
\begin{aligned}
& \frac{\mathrm{E}^{0}{ }_{380}}{\mathrm{E}^{0}{ }_{280}-1 / 2\left(\mathrm{E}^{0}{ }_{860}+\mathrm{E}^{0}{ }_{400}\right)} \\
& =\frac{1.78}{1.78-1 / 2(1.20+0.185)}=1.63 .
\end{aligned}
$$

With the constants established, the true optical density of cholic or chenodeoxycholic acid in an unknown can be calculated by obtaining the difference between the optical density at their absorption maxima and the average of the adjacent optical densities, and multiplying by the constant. For cholic acid the equation is

$$
E_{320}=1.67\left[E_{320}^{0}-1 / 2\left(E_{300}^{0}+E_{340}^{0}\right)\right]
$$

and for chenodeoxycholic acid the equation is

$$
\mathrm{E}_{380}=1.63\left[\mathrm{E}_{380}^{0}=1 / 2\left(\mathrm{E}_{380}^{0}+\mathrm{E}^{0}{ }_{400}\right)\right] \text {. }
$$

Having thus corrected the observed optical densities for background absorption, the true optical densities were used for calculating the bile acid concentrations according to the following equations:

$$
\begin{gathered}
\frac{\mathrm{E}_{320} \cdot \mathrm{K}^{\mathrm{D}_{380}}-\mathrm{E}_{380} \cdot \mathrm{K}^{\mathrm{D}_{320}}}{\mathrm{~K}^{\mathrm{D}_{380}} \cdot \mathrm{K}^{\mathrm{T}_{320}}-\mathrm{K}^{\mathrm{T}_{380}} \cdot \mathrm{K}^{\mathrm{D}_{320}}}=\begin{array}{c}
\text { Concentration of tri- } \\
\text { hydroxy acids }
\end{array} \\
\frac{\mathrm{E}_{380} \cdot \mathrm{K}^{\mathrm{T}_{320}}-\mathrm{E}_{320} \cdot \mathrm{K}^{\mathrm{T}_{380}}}{\mathrm{~K}^{\mathrm{D}_{380}} \cdot \mathrm{K}^{\mathrm{T}_{320}}-\mathrm{K}^{\mathrm{T}_{380}} \cdot \mathrm{K}^{\mathrm{D}_{320}}}=\begin{array}{c}
\text { Concentration of di- } \\
\text { hydroxy acids. }
\end{array}
\end{gathered}
$$
and

The values for $\mathrm{K}$ were obtained by plotting known concentrations of pure bile acids against the optical density at 320 and $380 \mathrm{m \mu}$ (Figure 3), and are as follows:

$\mathrm{K}^{\mathbf{T}}{ }_{320}=$ optical density at $320 \mathrm{~m} \mu$ per $\mathrm{mg}$. cholic acid $=37.4$ $\mathrm{K}^{\mathrm{D}_{320}}=$ optical density at $320 \mathrm{~m} \mu$ per $\mathrm{mg}$. chenodeoxycholic acid $=8.06$

$\mathrm{K}^{\mathrm{T}_{380}}=$ optical density at $380 \mathrm{~m} \mu$ per $\mathrm{mg}$. cholic acid $=4.54$ $\mathrm{K}^{\mathrm{D}_{380}}=$ optical density at $380 \mathrm{~m} \mu$ per $\mathrm{mg}$. chenodeoxycholic acid $=51.3$

Using these values in the preceding equations, the formulas for calculating the serum bile acid concentrations in $\mu \mathrm{g}$. per $\mathrm{ml}$. are obtained.

$\left(E_{320} \times 51.3-E_{380} \times 8.06\right) \times 1.06=\mu g$. of trihydroxy bile acid per ml. of serum

$\left(E_{380} \times 37.4-E_{320} \times 4.54\right) \times 1.06=\mu g$. of dihydroxy bile acid per $\mathrm{ml}$. of serum

The factor, 1.06, is the quotient of $\frac{1,000 \times 5 \times 30 / 25 \times 1 / 3}{1,883}$

in which the numerator contains dilution constants and conversion factors which are apparent when the method is

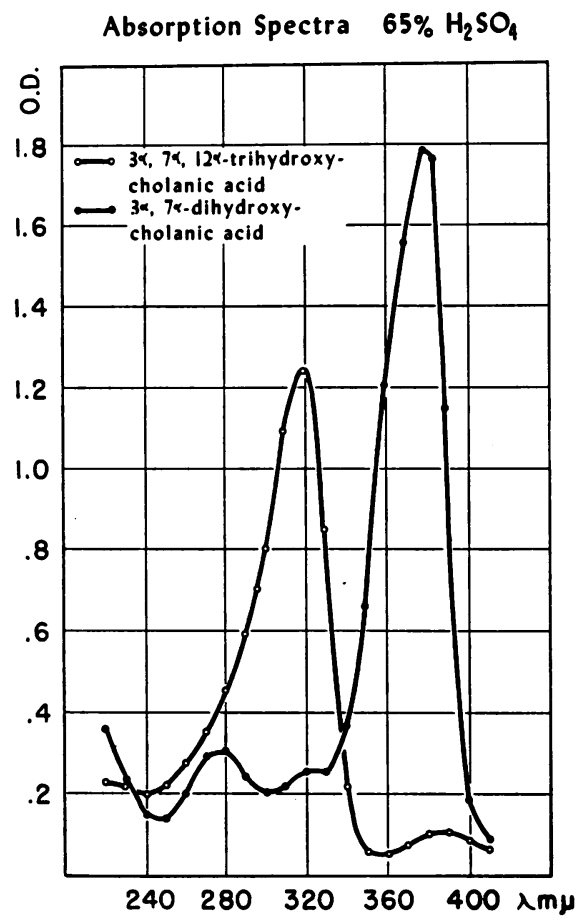

Fig. 2. Ultraviolet Absorption Spectra of Pure Bile Acids in 65 Per Cent Sulfuric Acid 
examined and the denominator is the numerical value of $\mathrm{K}^{\mathrm{D}_{380}} \cdot \mathrm{K}^{\mathrm{T}_{320}}-\mathrm{K}^{\mathrm{T}_{230}} \cdot \mathrm{K}^{\mathrm{D}_{320} \text {. }}$

In correcting for background absorption, it was necessary to assume that this absorption changes linearly between the wave lengths used. This assumption is probably not strictly correct but approximates the facts closely enough to provide a more accurate answer than would result if this correction were not made. The amount of deoxycholic acid in normal human serum is quite small, when compared with chenodeoxycholic acid, as judged from paper chromatograms, and for this reason the absorption maximum for chenodeoxycholic acid $(380 \mathrm{~m} \mu)$ was used for the calculations. The absorption maximum for deoxycholic acid is at $385 \mathrm{~m} \mu$. The optical density at this wave length, however, is only slightly greater than at $380 \mathrm{~m} \mu$; consequently the error involved is slight and does not contribute significantly to the total error of the method. Plotting the spectrum aids in detecting any erroneous optical density values caused by a disproportionately high background or inexplicable absorption peaks.

Standard glassware is used except that two of the four tubes (Tubes B and C, Figure 1) have ground glass tops which fit the separatory funnel. This simple modification reduces the amount of glassware needed for the procedure and greatly improves recoveries. It also permits the use of a convenient evaporating head consisting of an arm for attaching a suction line and a capillary tube (Figure 1).

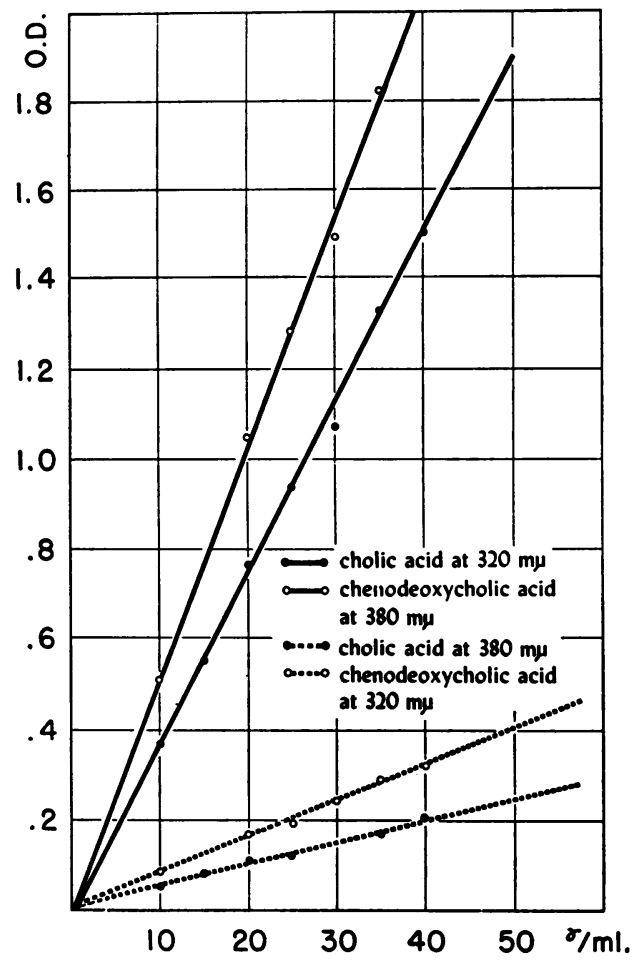

Fig. 3. Optical Density of Cholic Acm and Chenodeoxycholic AcID

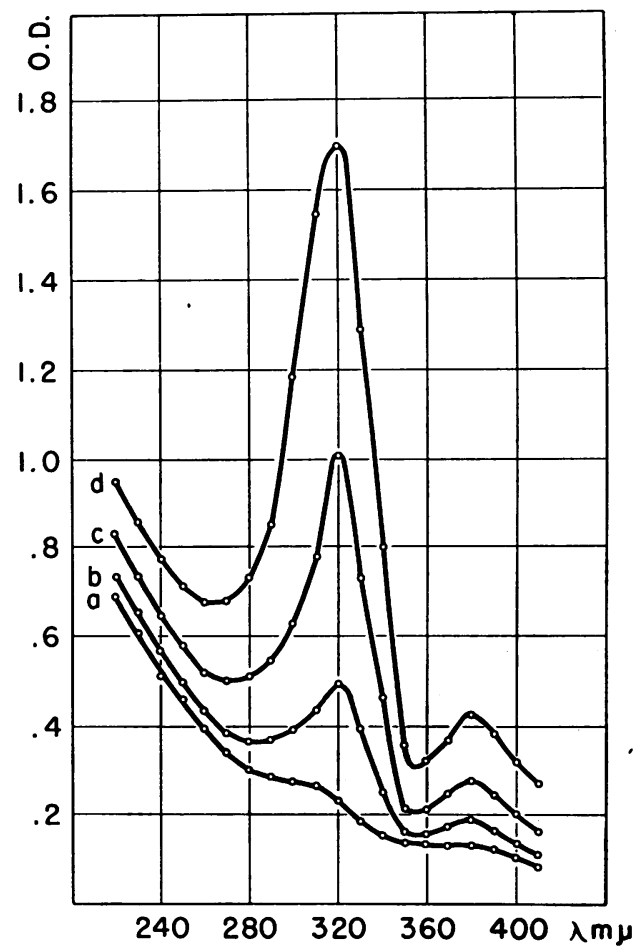

Fig. 4. Addition of Giycocholic Acid to Normal SERUM

Amounts added per ml. of serum: $a$ ) none, b) 0.015 mg., c) $0.040 \mathrm{mg}$., d) $0.080 \mathrm{mg}$.

\section{Experimental}

The addition of dihydroxy or trihydroxy bile acids to serum is paralleled by an increase in the appropriate optical density value as shown in Figures 4 and 5 . In these recovery experiments 15 to $100 \mu \mathrm{g}$. samples were used. Sodium glycocholate in water was added to the serum and chenodeoxycholic acid added to the alcoholic extract after partitioning with ether-petroleum ether. Results ranged from 74 to 91 per cent, mean 80 per cent. When solutions of pure bile acids were used in place of serum, recoveries were uniformly 100 plus or minus 5 per cent. Obviously there are a number of factors in serum which interfere with complete recoveries, and this limitation should be recognized when results are being compared and interpreted.

Duplicate determinations and normal values. In order to calculate the error of the method and the range of values to be expected in healthy subjects, duplicate determinations were done on single serum samples from 30 healthy persons ranging in age from 22 to 76 years, half of whom were women.

The average trihydroxy cholanic acid value was $1.4 \mu \mathrm{g}$. per $\mathrm{ml}$. with an estimated standard deviation of $0.8 \mu \mathrm{g}$. per $\mathrm{ml}$. and an estimated error of $0.8 \mu \mathrm{g}$. per $\mathrm{ml}$. The average dihydroxy cholanic acid value was $0.76 \mu \mathrm{g}$. per ml. with an estimated standard deviation of $1.4 \mu \mathrm{g}$. per $\mathrm{ml}$. and an estimated error of $0.36 \mu \mathrm{g}$. per $\mathrm{ml}$. The normal values 


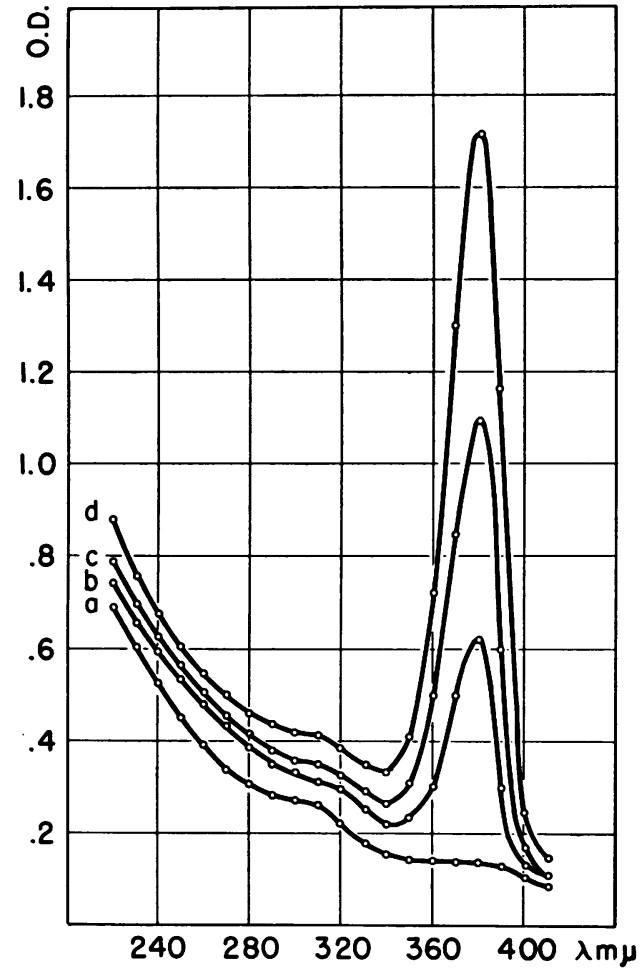

Fig. 5. Addition of Chenodeoxycholic Acid to Normal SERUM

Amounts added per ml. of serum: $a$ ) none, $b$ ) $0.015 \mathrm{mg}$., c) $0.040 \mathrm{mg} .$, d) $0.080 \mathrm{mg}$.

ranged from 0 to $3.4 \mu \mathrm{g}$. per ml. for trihydroxy acids and 0 to $1.9 \mu \mathrm{g}$. per ml. for dihydroxy acids. These values are lower than those previously reported with this method $(4,6)$ because correction for background absorption has been made as described in the section on calculation. The validity of the occasional zero value is supported by the observation that occasionally extracts of as much as $50 \mathrm{ml}$. of serum from a healthy subject fail to contain any bile acids when analyzed by paper chromatographic techniques capable of detecting as little as 2 to $4 \mu \mathrm{g}$. of bile acid.

The serum bile acid concentrations in these healthy subjects did not vary significantly with age or sex and serial determinations showed no trends which could be correlated with eating or diurnal changes.

The trihydroxy-dihydroxy concentration ratio, to be discussed later, is significant only when the concentration of at least one bile acid type is elevated above the normal range. The average ratio for the $\mathbf{3 0}$ healthy subjects was 1.9 but the range extended from 0 to 6 . This is because the error of the method and the standard deviations are of the same order of magnitude as the normal values, and consequently a wide range of ratios may occur in a healthy person by chance alone. The ratio becomes important, however, when the concentrations are elevated, as will be demonstrated in the following sections.
Patient material. In the two year period from July, 1955, through July, 1957, bile acid determinations were made on sera of 41 patients in whom the diagnosis of biliary obstruction or parenchymal liver disease was confirmed by laparotomy, biopsy, peritoneoscopy or autopsy and all of these are included in this report.

\section{RESULTS}

\section{Biliary obstruction}

There were 12 patients who had carcinoma or stone obstructing the bile ducts (Cases 1 to 12, Table II). All had elevated serum bile acid concentrations with a relatively greater increase in the trihydroxy acids resulting in a trihydroxydihydroxy ratio which was greater than 1 in all cases. An example of the ultraviolet absorption spectrum of the bile acids in the serum of a patient with biliary obstruction, Case 1 , is shown in the center panel of Figure 6. For comparison, the spectrum of normal serum is shown in the panel at the left. It can be seen that the absorption maxima of trihydroxy acids $(320 \mathrm{~m} \mu)$ and dihydroxy acids $(380 \mathrm{~m} \mu)$ are increased above normal and that a greater rise has occurred in the trihydroxy fraction. The trihydroxy ratio in this patient was 7.8.

A similar pattern was also noted in sera of jaundiced patients with obstruction or damage to the smaller biliary radicals within the liver such as that which is sometimes produced by chlorpromazine (Case 13) or carbarsone (Case 14). During the obstructive phase of viral hepatitis (Cases 15 and 16), and especially in the "cholangiolitic" type of viral hepatitis (Case 17) as described by Watson and Hoffbauer (11), the serum bile acid pattern is the same as that of ordinary biliary obstruction.

\section{Liver injury}

Patients with severe liver cell injury, in contrast to those with biliary obstruction, had a striking and disproportionate increase in the concentration of dihydroxy bile acids, completely reversing the trihydroxy-dihydroxy ratio to less than one. An example of this is shown in the third panel of Figure 6. This patient (Case 18) had advanced alcoholic cirrhosis and lapsed into hepatic coma several weeks after her blood was drawn for the serum bile acid determinations. It should be noted that the total serum bilirubin con- 
TABLE II

Serum bile acid concentrations and other laboratory studies in patients with hepato-biliary disorders

\begin{tabular}{|c|c|c|c|c|c|c|c|c|c|c|c|}
\hline \multirow[b]{2}{*}{ Diagnosis } & \multicolumn{2}{|c|}{ Serum bile acids } & \multirow[b]{2}{*}{ Ratio } & \multirow[b]{2}{*}{ Date } & \multirow{2}{*}{$\underset{\substack{\text { Serum } \\
\text { bili. } \\
1^{\prime} / \mathrm{T}^{*}}}{ }$} & \multirow[b]{2}{*}{$\begin{array}{c}\text { Thymol } \\
\text { turb. }\end{array}$} & \multirow[b]{2}{*}{$\begin{array}{l}\text { Ceph. } \\
\text { floc. }\end{array}$} & \multirow{2}{*}{$\begin{array}{l}\text { Serum } \\
\text { choles- } \\
\text { terol }\end{array}$} & \multirow{2}{*}{$\begin{array}{c}\text { Alk. } \\
\text { p'tase } \\
\text { KA } \\
\text { units† }\end{array}$} & \multirow{2}{*}{$\begin{array}{c}\text { Serum } \\
\text { protein } \\
\text { alb./glob. }\end{array}$} & \multirow[b]{2}{*}{ Comments } \\
\hline & $\begin{array}{l}\text { Trihy- } \\
\text { droxy }\end{array}$ & $\begin{array}{l}\text { Dihy- } \\
\text { droxy }\end{array}$ & & & & & & & & & \\
\hline & \multicolumn{2}{|c|}{$\mu g . / m l}$. & & & $m g . \%$ & & & mg. \% & & $G m . \%$ & \\
\hline 1. Carcinoma pancreas & 82.0 & 10.5 & 7.8 & $9-22-55$ & $19.8 / 31.9$ & & $\mathbf{0}$ & 392 & 67.5 & $2.6 / 5.2$ & Jaundice 6 wks. \\
\hline 2. Carcinoma pancreas & 74.4 & 6.7 & 11.1 & $12-14-55$ & $5.0 / 8.5$ & 2 & $\mathbf{0}$ & 155 & 57.4 & & Jaundice 3 days \\
\hline 3. Carcinoma pancreas & 24.9 & 6.0 & 4.2 & $2-8-57$ & $11.6 / 24.0$ & 2 & $\operatorname{tr}$ & & 52.6 & & Jaundice 7 wks. \\
\hline 4. Carcinoma pancreas & 24.9 & 2.1 & 12.0 & $4-30-56$ & $2.5 / 6.3$ & 11 & $\mathbf{0}$ & 176 & 62.6 & $2.8 / 3.6$ & Jaundice 22 wks. \\
\hline 5. Stone, C.B.D. $\ddagger$ & 4.5 & 2.6 & 1.7 & $11-7-55$ & $0.5 / 1.1$ & 3 & $\mathbf{0}$ & & 50.4 & & Jaundice 1 wk. \\
\hline 6. Stone, C.B.D. & 20.1 & 5.4 & 3.7 & $1-10-56$ & $9.0 / 16.3$ & 3 & & & & & Jaundice 2 wks. \\
\hline 7. Stone, C.B.D. & 80.0 & 19.5 & 4.1 & $3-26-56$ & $3.4 / 5.2$ & 3 & tr & & 37.0 & & Jaundice 1 wk. \\
\hline 8. Stone, C.B.D. & 3.5 & 1.0 & 3.5 & $2-23-56$ & $0.3 / 0.6$ & 3 & $1+$ & & 50.2 & & Jaundice 9 mo. \\
\hline \multirow{2}{*}{$\begin{array}{l}\text { 9. Stone, C. B.D. } \\
\text { 10. Carcinoma meta- } \\
\text { static, liver }\end{array}$} & 36.6 & 16.4 & 2.2 & $7-16-56$ & $11.2 / 21.6$ & 2 & 0 & & & $2.5 / 3.5$ & Jaundice 4 wks. \\
\hline & 45.0 & 9.1 & 4.9 & $12-9-55$ & $15.9 / 28.4$ & 3 & $3+$ & & 86.3 & $2.7 / 3.3$ & Jaundice 3 wks. \\
\hline static, liver & 18.4 & 6.0 & 3.1 & $2-8-56$ & $4.3 / 7.0$ & 4 & $\mathbf{0}$ & 167 & 67.5 & $2.9 / 3.6$ & Died 2-24-56 \\
\hline 12. Carcinoma C.B.D. & 23.7 & 6.2 & 3.8 & $12-29-55$ & $13.0 / 20.9$ & 4 & $\operatorname{tr}$ & & & & Jaundice 3 wks. \\
\hline $\begin{array}{l}\text { 13. Cholangiolitis, } \\
\text { chlorpromazine } \\
\text { 14. Cholangiolitis, }\end{array}$ & 33.6 & 12.6 & 2.7 & $8-2-55$ & $5.1 / 10.5$ & 3 & $\operatorname{tr}$ & & 54.4 & & Jaundice 1 wk. \\
\hline carbarsone & 76.1 & 31.5 & 2.4 & $12-8-55$ & $4.8 / 7.9$ & 9 & $4+$ & 276 & 55.6 & $3.0 / 3.8$ & Jaundice 4 days \\
\hline & 5.0 & 3.0 & 1.7 & $1-6-56$ & $1.3 / 2.5$ & 8 & $2+$ & 402 & 61.5 & $3.4 / 4.6$ & \\
\hline 15. Hepatitis, viral & 90.4 & 3.2 & 29.4 & $2-15-56$ & $5.1 / 8.9$ & 14 & $4+$ & & & & Jaundice 1 wk. \\
\hline & 7.0 & 0.9 & 7.8 & $2-23-56$ & $1.2 / 1.3$ & 26 & $4+$ & 288 & 28.8 & & \\
\hline 16. Hepatitis, viral & 22.1 & 11.3 & 2.0 & $2-9-57$ & $0.8 / 1.5$ & 16 & $3+$ & 153 & 23.4 & & Jaundice 2 days \\
\hline 17. Hepatitis, viral & 23.7 & 7.2 & 3.3 & $12-26-56$ & $3.7 / 7.0$ & 3 & 0 & & 24.0 & $2.9 / 3.8$ & Jaundice 6 wks. \\
\hline 18. Cirrhosis, portal & 10.8 & 24.2 & 0.5 & $11-30-55$ & $16.4 / 28.9$ & 3 & $3+$ & & 19.4 & $2.6 / 4.1$ & \\
\hline 19. Cirrhosis, portal & 6.3 & 17.2 & 0.4 & $9-26-55$ & $1.0 / 2.3$ & 9 & $4+$ & & 15.8 & $1.4 / 4.6$ & Died 10-1-55 \\
\hline 20. Cirrhosis, portal & 0 & 18.8 & 0 & $9-13-55$ & $3.1 / 11.5$ & & $3+$ & 106 & & & Died 10-55 \\
\hline 21. Cirrhosis, portal & 0 & 0.8 & $\mathbf{0}$ & $11-22-55$ & $1.2 / 3.4$ & 4 & $4+$ & & & $1.6 / 5.3$ & Died 11-30-55 \\
\hline & 0 & 10.5 & $\mathbf{0}$ & $11-30-55$ & & & & & & & \\
\hline 22. Cirrhosis, portal & 17.1 & 27.3 & 0.6 & $12-2-55$ & $18.6 / 32.8$ & 4 & tr & 142 & 36.5 & $2.2 / 4.2$ & \\
\hline & 7.1 & 9.8 & 0.7 & $1-16-56$ & $1.9 / 4.1$ & 5 & $2+$ & 191 & & & \\
\hline & 0 & 21.9 & 0 & $12-7-56$ & $1.7 / 3.1$ & 3 & $3+$ & & 27.8 & & Died 12-7-56 \\
\hline 23. Cirrhosis, portal & 3.1 & 5.2 & 0.6 & 4-26-56 & $0.7 / 1.9$ & 6 & $4+$ & & 12.7 & $1.8 / 5.2$ & Died 5-2-56 \\
\hline 24. Cirrhosis, portal & 0.7 & 4.9 & 0.1 & $8-28-56$ & $9.0 / 15.5$ & 9 & $1+$ & 93 & 30.0 & $1.9 / 3.8$ & Died 8-30-56 \\
\hline 25. Cirrhosis, portal & 8.4 & 22.6 & 0.4 & $6-21-56$ & $2.8 / 10.2$ & & $3+$ & & & & \\
\hline & 2.2 & 11.3 & 0.2 & 1-19-57 & $0.7 / 1.7$ & 8 & $4+$ & & 15.4 & $1.8 / 4.9$ & \\
\hline & 0.1 & 1.0 & 0.1 & $7-9-57$ & $1.0 / 3.1$ & & & 148 & 6.5 & $2.0 / 4.0$ & Died 8-25-57 \\
\hline 26. Cirrhosis, portal & 2.5 & 4.3 & 0.6 & $8-23-56$ & $0.9 / 2.1$ & 3 & $2+$ & 99 & 10.8 & $1.8 / 3.0$ & Died 8-31-56 \\
\hline 27. Cirrhosis, portal & 8.6 & 30.1 & 0.3 & $9-22-56$ & $11.8 / 26.3$ & 5 & $4+$ & 44 & 29.3 & & \\
\hline & 5.9 & 22.0 & 0.3 & $9-25-56$ & & & & & & & Died 9-27-56 \\
\hline 28. Cirrhosis, portal & $\mathbf{0}$ & 24.4 & $\mathbf{0}$ & $1-25-57$ & $3.6 / 8.9$ & 5 & $4+$ & 117 & 11.5 & $1.7 / 5.1$ & Died 1-27-57 \\
\hline 29. Cirrhosis, portal & $\mathbf{0}$ & 2.4 & $\mathbf{0}$ & $11-27-56$ & $0.3 / 1.0$ & 5 & $3+$ & & & $2.6 / 4.0$ & Died 4-17-57 \\
\hline 30. Cirrhosis, post necrotic & 18.2 & 45.5 & 0.4 & $8-2-56$ & $9.1 / 20.0$ & 6 & $3+$ & 115 & & & Died 1-57 \\
\hline 31. Cirrhosis, post necrotic & 6.8 & 9.1 & 0.8 & $5-1-56$ & $0.5 / 1.7$ & 17 & $4+$ & 182 & 14.8 & $2.6 / 4.5$ & Died 10-24-57 \\
\hline 32. Cirrhosis, post necrotic & $\mathbf{0}$ & 55.0 & $\mathbf{0}$ & $8-16-56$ & $9.4 / 13.8$ & 3 & $2+$ & 39 & 23.6 & $3.2 / 2.5$ & \\
\hline & $\mathbf{0}$ & 45.4 & $\mathbf{0}$ & $8-28-56$ & $16.3 / 28.8$ & 3 & $3+$ & & 23.3 & & Died 9-10-56 \\
\hline 33. Cirrhosis, post necrotic & 5.5 & 43.5 & 0.1 & $9-25-56$ & $7.7 / 14.7$ & 19 & $4+$ & 114 & 18.4 & $1.8 / 5.4$ & Died 10-2-56 \\
\hline 34. Cirrhosis, post necrotic & 0 & 13.1 & $\mathbf{0}$ & $12-20-56$ & $1.5 / 3.5$ & 7 & $4+$ & 85 & & $2.2 / 3.4$ & Died 2-12-57 \\
\hline 35. Cirrhosis, biliary & 29.8 & 4.6 & 6.5 & $11-22-55$ & $8.7 / 14.8$ & 12 & $4+$ & & 82.8 & & \\
\hline & $\mathbf{0}$ & 2.5 & $\mathbf{0}$ & $12-27-56$ & $9.2 / 19.1$ & 9 & $3+$ & & & $2.0 / 3.0$ & Died 12-31-56 \\
\hline 36. Cirrhosis, biliary & 0.2 & 0.5 & 0.4 & $1-2-57$ & $1.9 / 4.7$ & 4 & $3+$ & & 35.8 & $3.4 / 3.1$ & Died 3-30-57 \\
\hline 37. Cirrhosis, biliary & 2.8 & 3.2 & 0.9 & $4-30-56$ & $9.3 / 18.0$ & 2 & $2+$ & & 40.5 & $2.4 / 3.2$ & Died 4-28-56 \\
\hline 38. Hepatitis, viral & 25.8 & 30.4 & 0.8 & $4-27-56$ & $8.8 / 16.5$ & 12 & $4+$ & 116 & 32.3 & $2.7 / 3.3$ & Died 5-16-56 \\
\hline & $\mathbf{0}$ & 11.0 & $\mathbf{0}$ & $5-6-56$ & $15.9 / 28.4$ & 9 & $4+$ & & & $2.1 / 3.3$ & \\
\hline 39. Hepatitis, viral & 23.9 & 31.7 & 0.8 & $7-18-56$ & $3.5 / 5.1$ & 10 & $4+$ & & 24.8 & $2.1 / 3.3$ & \\
\hline & 5.9 & 14.4 & 0.4 & $7-23-56$ & $5.6 / 10.1$ & & & 78 & & & Died 8-10-56 \\
\hline 40. Cirrhosis, portal & 3.1 & 2.0 & 1.6 & $11-22-55$ & $0.8 / 2.5$ & & $1+$ & & & & \\
\hline & 4.7 & 18.6 & 0.3 & $1-15-56$ & $0.8 / 2.2$ & 4 & $4+$ & & & $2.3 / 4.8$ & \\
\hline & 4.4 & 2.0 & 2.2 & $1-25-56$ & $0.4 / 0.5$ & 3 & 0 & & & & \\
\hline 41. Cirrhosis, portal & 1.4 & 3.9 & 0.4 & $6-21-57$ & $2.8 / 4.5$ & 5 & $3+$ & & & & \\
\hline & 73.3 & 14.7 & 5.0 & $6-27-57$ & $2.0 / 3.4$ & 5 & $3+$ & & 40.5 & & \\
\hline
\end{tabular}

* One minute/total.

† Alkaline phosphatase, King-Armstrong units.

$\ddagger$ Common bile duct. 


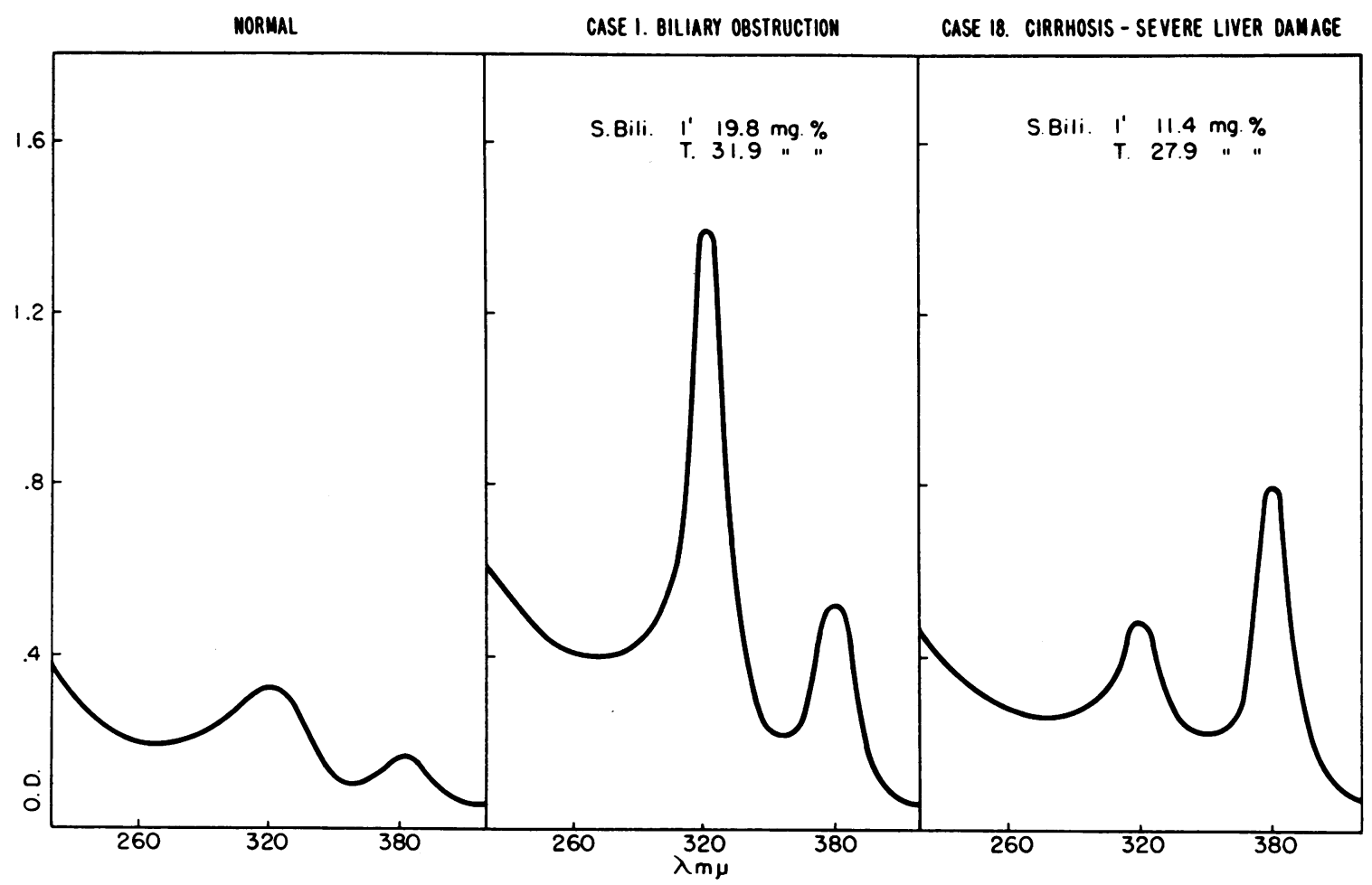

Fig. 6. Ultraviolet Absorption Spectra of Bile Acids in Sera of Patients With (Left) Normal Serum, (Center) Biliary Obstruction and (Right) Liver Damage

centrations of the two patients shown in Figure 6 are of the same order of magnitude.

The severity of the liver damage associated with this reversed bile acid ratio has been clearly demonstrated to us by the fact that slightly less than one-half the patients died within a few weeks or months following this reversal (Cases 19 to 39). An additional one-fourth are in the terminal stages of their illness.

The reversed ratio also occurs during acute liver injury and will return to one or greater than one as the patient recovers. An example of this is Case 40. This man had cirrhosis associated with chronic alcoholism. He was admitted to the hospital in November, 1955, because of a peptic ulcer. The bile acids were very slightly elevated, but the ratio was 1.6. He returned the following January after a drinking bout, in a state of acute alcoholism and impending delirium tremens. The injury to his liver was reflected by a rise in the dihydroxy bile acids causing a reversal of the trihydroxy-dihydroxy ratio to 0.3 . The Hanger test became $4+$ but the serum bilirubin changed very little. With medical care and gradual re- covery, the ratio returned to a value of 1.110 days later, and the Hanger test became negative. It should be emphasized here that if only cholic acid had been measured, relatively little change would have been noted.

The prognostic value of the trihydroxy-dihydroxy bile acid ratio is illustrated quite well by Cases 25 and 33. Case 25 was a man with cirrhosis associated with alcoholism, who had ascites and was facing hepatic coma upon his admission in December, 1955. Following a period of hospital care, salt restriction, diuresis, bed rest, a good diet and abstinence from alcohol, the patient became more alert and the ascites disappeared. This improvement was reflected by a fall in the serum bilirubin and bile acid concentrations. The ratio, however, remained reversed $(0.7)$ and the Hanger test changed from trace to $2+$. The patient returned one year later in deep coma and died a few hours after admission; at this time, the trihydroxy-dihydroxy ratio was zero because of the complete absence of cholic acid.

The second example, Case 33, was a 44 year old woman admitted in late September, 1956, having 
had jaundice for two months. No stigmata of chronic liver disease were present and there was no ascites. The patient became confused on the fourth hospital day and died in coma on the eighth hospital day. The serum bile acids were determined two days after admission while the patient was alert, active and had no signs to suggest that she would die in a few days. The approximately 50 -fold increase of dihydroxy acids above normal, however, with a comparatively minor rise of trihydroxy acids, strongly suggested the extensive liver damage which was subsequently found at autopsy as shown by the photomicrograph in Figure 7. A similar disproportionate rise in the serum dihydroxy acids was noted in Case 32, a 19 year old girl. In this instance, the ultraviolet absorption spectrum of the serum resembled very closely that of pure chenodeoxycholic acid, which was easily separated from her serum by means of paper chromatography. This girl died in hepatic coma four weeks later.

\section{DISCUSSION}

From the material presented, there are several observations which deserve emphasis. The first of these is that the differential analysis of the two bile acid types provides more valuable information than the measurement of only a single bile acid. This is so because the ratio of the concentration of the two major types of bile acids is of greater importance than their individual concentrations. If only the trihydroxy bile acid concentration (mostly cholic acid) is compared with the other liver function studies shown in Table II, it is clear that relatively little helpful information is obtained concerning either the liver's condition or the cause of the jaundice. This was also the conclusion Sherlock and Walshe made from their careful study of serum cholates in liver disease (1). When both types of bile acids are measured, however, differences in the quantitative relationships between the two types, simply expressed as the trihydroxy-dihydroxy ratio, immediately become of some importance, especially as a measure of the extent of liver injury. When liver damage is extensive, the ratio ranges from less than 1 to 0 . With biliary obstruction, on the other hand, serum bile acid concentrations increase, but the ratio will be greater than one, sometimes reaching a

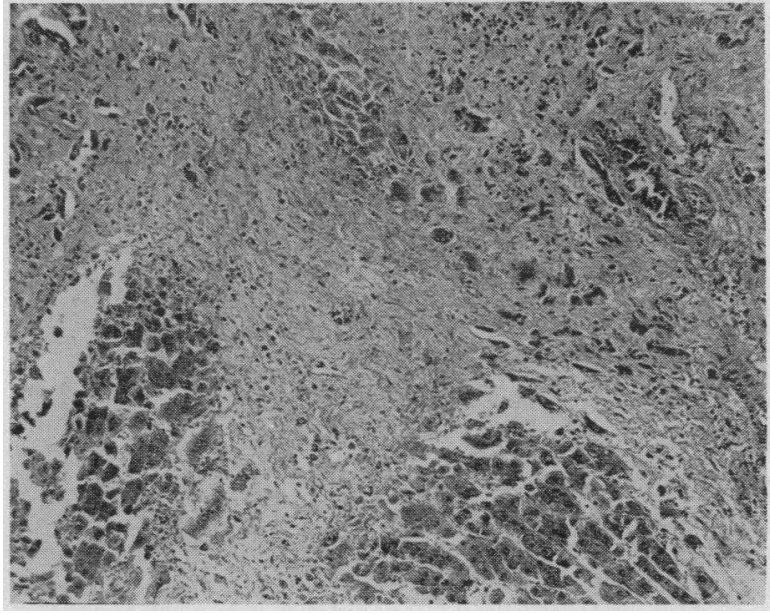

Fig. 7. Photomicrograph of Liver from Case 33 Showing Extensive Liver Damage

value of 20 to 30 or more. When the obstruction is prolonged to the point of extensive liver damage, however, as it was in Case 35, serum bile acid concentrations fall, and the ratio is lowered.

It should be stressed at this point that serum bile acid determinations as described in this paper will not disclose the location of the biliary obstruction and thus will not provide an answer to the often difficult question of whether the jaundice must be dealt with surgically or treated medically; in other words, whether the disease involves the smaller biliary radicals within the liver, or the extrahepatic bile ducts.

\section{Pruritis}

The relationship of bile acids to the pruritis of jaundice is by no means clarified by this study. Bile acid concentrations were found to be elevated in the sera of all jaundiced patients who had pruritis, but no pruritis occurred at any time in several patients who had very high serum bile acid concentrations (Cases 2, 33).

In order to study this point more fully, a patient with alcoholic cirrhosis (Case 41) was fed one $\mathrm{Gm}$. of pure cholic acid in a gelatin capsule daily for seven days, at which time the serum trihydroxy acid reached a concentration of $73.3 \mu \mathrm{g}$. per $\mathrm{ml}$., a value exceeding that which accompanied itching in other individuals, but no pruritis occurred in this patient. It is well known, of course, that the administration of commercial bile salt preparations to some jaundiced subjects will pro- 
duce pruritis (12), but practically all such preparations, except those composed of dehydrocholic acid only, contain other constituents of the bile besides bile acids. Obviously the question of whether elevated serum bile acid concentrations are only associated with pruritis or actually cause it will require additional information before a definite answer can be provided.

\section{The bile acid ratio}

Mechanisms responsible for the reversed bile acid ratio in severe liver injury have not been elucidated. From the information at hand it is not unreasonable to suspect that the activity of a 12 $\alpha$-hydroxylating enzyme is deficient. Bergström and Sjövall (13) and Mahowald and associates (14) have shown in rats that chenodeoxycholic acid is not an intermediate in the formation of cholic acid. Bergström (15) has also demonstrated that $3 \alpha, 7 \alpha$-dihydroxycoprostane is readily converted to cholic acid as well as chenodeoxycholic acid in rats. If these pathways of bile acid synthesis in the rat are also important routes in the human liver then the increased serum concentration of chenodeoxycholic with liver injury may result from degradation of the side chain of the molecule to a 24 carboxy acid before hydroxylation at the $12 \alpha$ position can occur. Evidence to support such speculation is provided by the observation (16) that the 12 position is less vulnerable to oxidation than the 7 position, partly because of hindrance by the angular methyl group at Carbon 13 (17). The enterohepatic return of predominantly dihydroxy bile acids to the damaged liver, which cannot re-excrete them normally, would also contribute to the quantity of dihydroxy acid in the serum. A more prolonged exposure of bile acids to these hydroxylating enzymes has been suggested by Rudman and Kendall (5) to explain the increased proportion of trihydroxy acids in serum with biliary obstruction.

\section{SUMMARY AND CONCLUSIONS}

1. A quantitative method for the simultaneous differential determination of serum trihydroxy and dihydroxy bile acids is described. Normal values have been established for a group of healthy subjects and variations from the normal have been studied in 41 patients with various hepatobiliary disorders.

2. With severe liver injury a disproportionate increase in the dihydroxy bile acid concentration reduced the trihydroxy-dihydroxy ratio to less than 1.0.

3. Persistence of this reversed ratio is frequently followed by coma, death or both. When the ratio is only temporarily reversed, as with acute or transient liver injury, improvement or recovery of the patient is paralleled by a rise in the ratio towards a value of 1.0 or more. This is helpful in estimating the extent of liver injury and monitoring its course.

4. With biliary obstruction, whether intra- or extrahepatic, the serum bile acid concentrations are increased but the ratio remains greater than 1.0 .

\section{ACKNOWLEDGMENTS}

This research began in Dr. C. J. Watson's laboratory as a project under his direction. His advice and many helpful suggestions are greatly appreciated.

The technical assistance of Janie Figen, Olga Hammerstrom and Gale Williams is gratefully acknowledged.

\section{REFERENCES}

1. Sherlock, S., and Walshe, V. Blood cholates in normal subjects and in liver disease. Clin. Sci. 1948, 6, 223.

2. Carey, J. B., Jr., Figen, J., and Watson, C. J. Bile acids in normal human serum with comparative observations in patients with jaundice. J. Lab. clin. Med. 1955, 46, 802.

3. Carey, J. B., Jr. Chenodeoxycholic acid in human blood serum. Science 1956, 123, 892.

4. Carey, J. B., Jr. The serum dihydroxy-trihydroxy bile acid ratio in liver and biliary tract disease (abstract). J. clin. Invest. 1956, 35, 695.

5. Rudman, D., and Kendall, F. E. Bile acid content of human serum. I. Serum bile acids in patients with hepatic disease. J. clin. Invest. 1957, 36, 530.

6. Schiff, L. Pathologic physiology of hepatitis in Hepatitis Frontiers, F. W. Hartman, G. A. Logrippo, J. G. Mateer, and J. Barron, Eds. Boston, Little, Brown and Co., 1957, p. 31.

7. Josephson, B. The determination of cholic acids in blood. Biochem. J. 1935, 29, 1519.

8. Minibeck, H. Beiträge zur quantitativen fluoreszenzphotometrischen Mikroanalyse. II. Mitteilung: Eine Methode zur Bestimmung der Gallensäuren im Serum und im Serösen Flüssigkeiten mit dem "Fluoroquant." Biochem. Z. 1938, 297, 29. 
9. Mosbach, E. H., Kalinsky, H. J., Halpern, E., and Kendall, F. E. Determination of deoxycholic and cholic acids in bile. Arch. Biochem. 1954, 51, 402.

10. Brice, B. A., and Swain, M. L. Ultraviolet absorption method for the determination of polyunsaturated constituents in fatty materials. J. optical Soc. Amer. 1945, 35, 532.

11. Watson, C. J., and Hoffbauer, F. W. The problem of prolonged hepatitis with particular reference to the cholangiolitic type and to the development of cholangiolitic cirrhosis of the liver. Ann. intern. Med. 1946, 25, 195.

12. Ahrens, E. H., Jr., Payne, M. A., Kunkel, H. G., Eisenmenger, H. J., and Blondheim, S. H. Primary biliary cirrhosis. Medicine (Baltimore) 1950, 29, 299.

13. Bergström, S., and Sjövall, J. Occurrence and metabolism of chenodeoxycholic acid in the rat. Bile acids and steroids 13. Acta chem. scand. 1954, 8, 611.

14. Mahowald, T. A., Matschiner, J. T., Hsia, S. L., Richter, R., Doisy, E. A., Jr., Elliott, W. H., and Doisy, E. A. Metabolism of deoxycholic acid-24-C $\mathrm{C}^{14}$ and chenodeoxycholic acid-24- $\mathrm{C}^{\mathbf{1 4}}$ in the rat. $\mathrm{J}$. biol. Chem. 1957, 225, 781.

15. Bergström, S., and Lindstedt, S. The formation of cholic acid from $3 \alpha, 7 \alpha$-dihydroxycoprostane in the rat. Biochim. Biophys. Acta 1956, 19, 556.

16. Fieser, L. F., and Rajagopalan, S. Oxidation of steroids. III. Selective oxidations and acylations in the bile acid series. J. Amer. chem. Soc. 1950, 72, 5530 .

17. Barton, D. H. R. The application of the method of molecular rotation differences to steroids. III. Steroidal hormones and bile acids. J. chem. Soc. 1946, 1116. 